\title{
ASSESSMENT OF VEGETATION COOLING EFFECT ON THE SURROUNDING THERMAL ENVIRONMENT IN BLOCK SCALES
}

\author{
Liu Yipeng, Guoyin Cai \\ (Department of Remote Sensing Science and Technology, School of Geomatics and Urban Informatics, Beijing University of Civil \\ Engineering and Architecture, 100044) \\ Email: cgyin@bucea.edu.cn
}

KEY WORDS: urban heat island; green cooling effects; block scale

\begin{abstract}
:
The growing coverage of impervious surfaces within cities has resulted in a decrease in vegetation areas, which in turn has caused the temperature increase in urban region. It has proved that vegetation plays an important role in mitigating urban heat island (UHI) effects such that the city managers and planners have paid more attention on how to plan green lands in city planning related projects. This paper focuses on the detection of the mean land surface temperature (LST) change in residential blocks in Changchun where citizens are have common daily lives. Then, according to the interactive extraction of high spatial resolution images, the regions with great changes in Changchun city during 2016 and 2019 are analyzed and compared with the average surface temperature of each block. According to statistical methods, the mitigation effect of the green space on the plot was obtained. It is helpful for city managers or planners to create a livable environment for citizens.
\end{abstract}

\section{INTRODUCTION}

This paper studies Changchun city and its surrounding vegetation from the scale level of patches (patch characteristics), revealing the influence of urban impervious layer and surrounding vegetation on urban thermal environment.

With the intensification of urbanization and climate warming, the urban thermal environment has gradually deteriorated and has become one of the major ecological environment problems facing cities in the 21 st century. How to improve the thermal environment through reasonable measures is currently a hot topic in research. Urban impervious layer and surrounding vegetation have great influence on the urban thermal environment. Therefore, it is of great significance to study the relationship between the characteristics of urban impervious layer and the thermal environment to improve the urban thermal environment.

In the process of urbanization, great changes have taken place in the structure and type of the earth's surface. The growth and scale expansion of urban construction land have occupied a large amount of land resources. While the urban construction land represented by impermeable layer is expanding rapidly, a series of environmental problems such as global warming brought about by urbanization have gradually emerged. The change of urban thermal environment affects urban residents all the time and is closely related to people's daily life. How to improve the city's thermal environment, build an ecological city and how to improve the quality of people's living environment have become issues that the society attaches great importance to ${ }^{[1-2]}$.
Vegetation helps maintain the city's heat balance by affecting the water and heat circulation between the atmosphere and the surface. In hot weather, the plants around the building can block the direct radiation of the sun on the roof, windows and walls of the building and block the reflected radiation of the surrounding ground objects, thus changing the energy balance of the building and reducing the energy consumption of air conditioning and refrigeration. At the same time, the green vegetation changes water into steam through transpiration, reduces the surface temperature of the vegetation and increases the water content in the surrounding air, making the temperature near the ground of the green space lower than that in the building area, thus forming the "oasis effect".

In the whole city, increasing the area of green vegetation can absorb a large amount of greenhouse gases such as carbon dioxide and reduce the overall heat capacity of the city surface, thus adjusting the energy balance of the whole city, weakening the heat island ${ }^{[3-4]}$ effect of the city on the micro and macro scales, improving the urban thermal environment, and providing more comfortable urban living environment and leisure activities for citizens. Urban vegetation can not only have an important impact on the urban environment and residents' lives, but also reflect to a certain extent the changes in urban spatial pattern and ecological environment under the influence of human activities. It can timely and accurately grasp the distribution, structural characteristics and dynamic changes in space and time of urban vegetation, analyze the current status and future change trend of vegetation, and discuss the mode of action and specific effects of vegetation in changing the urban thermal environment. It is important to maintain the regional ecological balance. Improving the city's thermal environment and ensuring the quality of life of city residents will all play an 
important role and have important scientific and practical values. They will play a pivotal role in the city's future scientific planning.

To sum up, the study of urban thermal environment based on patches is not only helpful to understand the changes of urban land use and cover, but also to study the effects of vegetation on urban thermal environment, and to provide theoretical support and suggestions for alleviating the state of urban thermal environment.

\section{RESEARCH CONTENT AND SIGNIFICANCE}

\subsection{Research Significance}

Changchun City is located on the eastern edge of Songnen Plain, a transportation hub in northeast China, an important industrial base and one of the largest cities in the country. It is an important automobile industry and agricultural product processing base in the country. With the increase of man-made heat caused by industrial production, household stoves and motor vehicle emissions, as well as the development and construction of the city, the temperature in Changchun city has gradually increased, showing an obvious heat island effect, which has brought significant impact on residents' life, production and ecological city construction.

The increasingly serious urban thermal environment is mainly due to the comprehensive effect of three factors: the structural characteristics of urban underlying surface, urban man-made heat and climatic conditions. Changes in the structural characteristics of the land surface mean that natural vegetation is usually replaced by impermeable and impermeable surfaces such as asphalt, cement, metal, etc., eventually changing the distribution of water and vegetation in urban areas, transforming permeable, low-temperature, high-humidity natural surface (non-construction land) into impermeable, high-temperature and low-humidity urban surface (construction land).

The urbanization process has prompted many cities to develop in the form of plane expansion and three-dimensional expansion, which has led to higher floor area ratio of buildings in cities, made the heat collected by cities difficult to diffuse, and further intensified the intensity of urban heat island. Another result of urbanization is that population and industry are highly concentrated in cities and the energy produced by human beings is increasing. There are three main causes of man-made heat in urban space: high energy-consuming heat emission from urban industrial and mining enterprises; the urban population is increasing, and the heat emitted by the human body is also increasing. The improvement of social living standards has led to the rapid growth of the number of urban motor vehicles and the widespread use of household appliances such as air conditioners and refrigerators by urban residents. It has also greatly increased the energy consumption for living and accelerated the release of man-made energy for living in urban space. Therefore, the problem of urban thermal environment, as a comprehensive embodiment of urban ecological environment, has attracted increasing attention.

Therefore, it is necessary to discuss how to better alleviate the urban heat island effect from the perspective of urban spatial layout, which will eventually guide urban planning and ecological environment construction and improve the living environment.

\subsection{Research Content}

This paper takes the urban patches around Changchun city as the research object. Firstly, the image data of Changchun City in 2016 and 2019, namely panchromatic and multispectral image data, of Gaofen No. 2 were obtained. Then, the places with great changes in Changchun city in 2016 and Changchun city in 2019 are merged and screened. Through supervised classification and interactive extraction, urban patches are classified and their areas are calculated. Then the temperatures in each patch are calculated under Arc GIS and ENVI platforms respectively, so as to obtain the thermal environmental effects of urban patches in 2016 and 2019. Finally, the impervious layer and its corresponding surface temperature inversion results in 2016 and 2019 are compared to reveal the impact of urban increase or decrease on the urban thermal environment.

\subsection{Flow Chart}

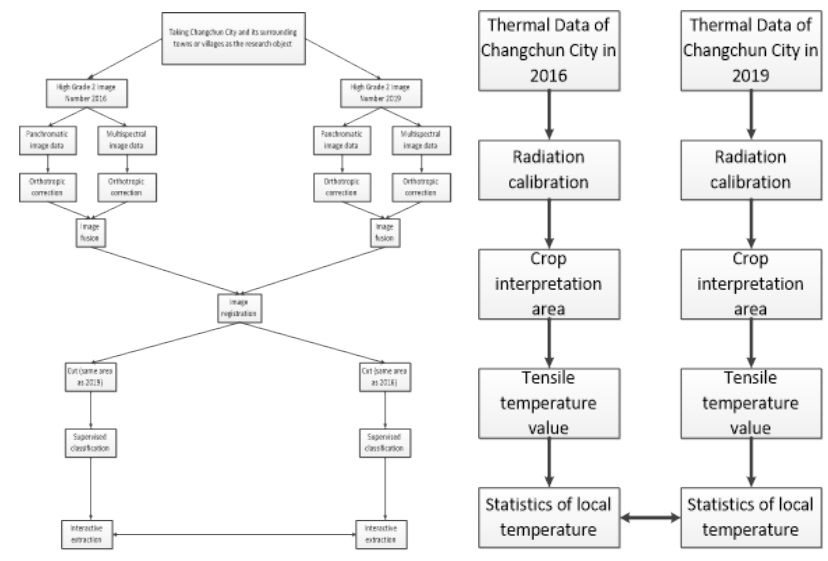

\section{DATA AND METHODS}

\subsection{Survey of Research Area}

Changchun city is located at $12509^{\prime}$ to $12548^{\prime}$ east longitude and $4346^{\prime}$ to $4358^{\prime}$ north latitude. It is located at the eastern edge of Songnen plain and is located in the middle of Changchun platform. it is a plain city. The Yitong river flows through the east of the city. The frost-free period is about 140 days, with annual precipitation of $567 \mathrm{~mm}$, and the annual average temperature in the urban area is $4.9^{\circ} \mathrm{C}$, which is higher $(0.1 \sim 0.5)^{\circ} \mathrm{C}$ than that in the surrounding counties (cities). Changchun is a transportation hub in northeast China. It is one of the country's important industrial bases and megacities. It is known as "automobile city", "forest city" and "movie city". It is also an important base for automobile industry, agricultural products processing industry and a city for science, education, culture and trade. With the increase of man-made heat caused by industrial production, household stoves and motor vehicle emissions, as well as the changes in urban land use types and underlying thermodynamic properties caused by urban development and construction, the temperature in Changchun urban area has a gradually rising trend, which has brought significant impacts on residents' life, production activities and eco-city construction.

non-specialists.

\subsection{Research Data}

This paper uses Gaofen No.2 data on May 19, 2016 and Gaofen No.2 data on June 16, 2019. After preprocessing the two image 
data, the two regions with large topographic map changes are cut out, and supervised classification is carried out respectively to extract the impermeable layer in the cut-out region. This paper also uses Landsat 8 image on May 19, 2016 and Landsat 8 image on June 161, 2019. The two image data are combined with ENVI software to carry out surface temperature inversion. Cut out the same places as the above areas and make comparative analysis.

\subsection{Research Methods}

3.3.1 Inversion of Surface Temperature: The DN value is converted into radiance after radiation calibration, and the calibration coefficient is provided by the Landsat official website ${ }^{[5]}$. The calculation formula is as follows:

\section{$\mathrm{L}=\mathrm{Gain} \cdot \mathrm{DN}+\mathrm{Bias}$}

Where: 1 is radiance (unit $\mathrm{w} \cdot \mathrm{m}^{-2} \cdot \mathrm{sr}-1 \cdot \mu \mathrm{m}-1$ ), $\mathrm{DN}$ is pixel gray value, Gain is gain (Gain=0.055158), Bias is offset value (Bias=1.2378)

After obtaining the heat radiation brightness L, convert it into brightness temperature:

$$
\mathrm{T} 6=\frac{K 2}{\ln (1+K 1 / L)}
$$

Where $\mathrm{T} 6$ is brightness temperature (unit $\mathrm{k}$ ), $\mathrm{K} 1$ and $\mathrm{K} 2$ are constants $(\mathrm{K} 1=607.76 \mathrm{w} \cdot \mathrm{m}-2 \cdot \mathrm{sr}-1 \cdot \mu \mathrm{m}-1, \mathrm{~K} 2=1260.56 \mathrm{~K})$.

3.3.2 Change Monitoring: Firstly, the regions with great changes between 2016 and 2019 are simply extracted through visual observation, and then supervised classification is carried out under ENVI platform. In this paper, the supervised classification chooses the maximum likelihood classification, because other classification methods have low accuracy, such as the minimum distance classification, which only considers the distance from the sample to be classified to the center of each category without considering the distribution of known samples, so its classification speed is fast, but its accuracy is not high. However, the maximum likelihood classification not only considers the distance between the sample to be classified and the center of the known class, but also considers the distribution characteristics of the known class, so its classification accuracy is higher than that of the minimum distance classification and other classification methods.

\section{RESULTS AND ANALYSIS}

\subsection{Extraction Results and Inversion Results of Surface Temperature}

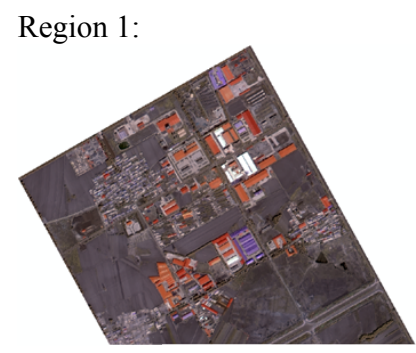

2016a

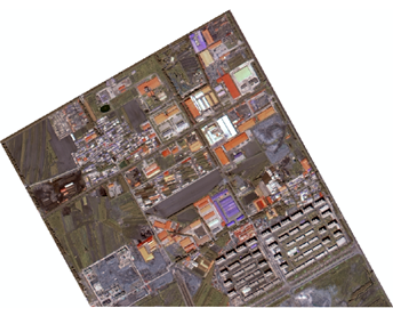

$2019 \mathrm{a}$

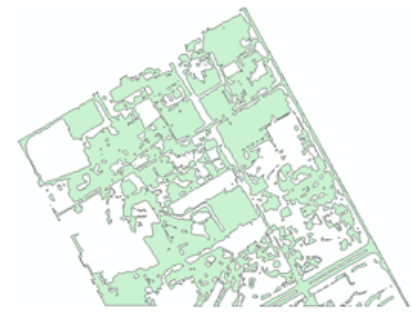

$2016 \mathrm{a}$

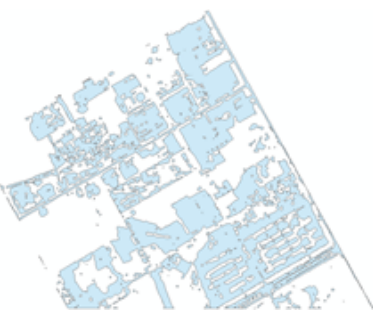

$2019 \mathrm{a}$
Figure 2. an impermeable layer in the extraction area

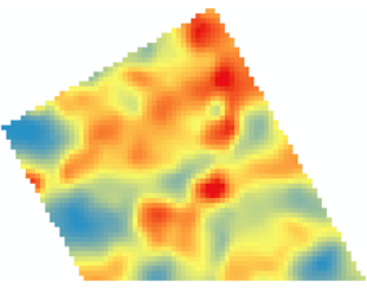

$2016 \mathrm{a}$

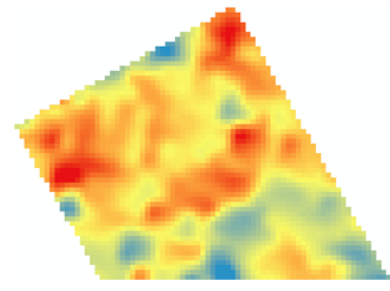

$2019 \mathrm{a}$
Figure 3. Inversion Results of Area 1 Surface Temperature

Although there are newly built buildings in this area, the temperature change before and after the building is built is not obvious. The temperature around the newly built buildings in 2019 is the same as that before the building is built.

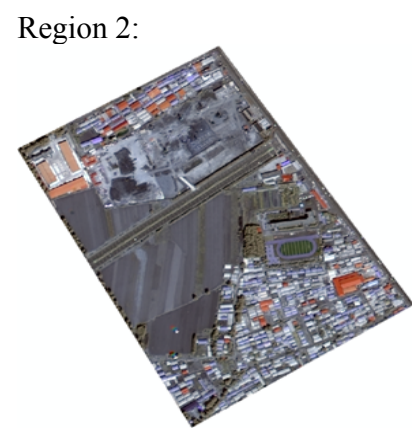

$2016 b$

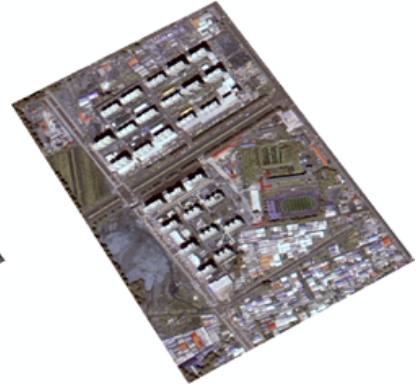

$2019 b$
Figure 4. Selected Area 2

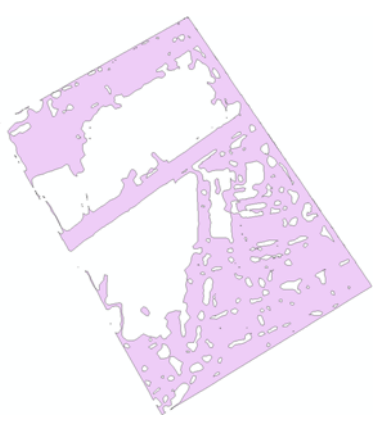

$2016 b$

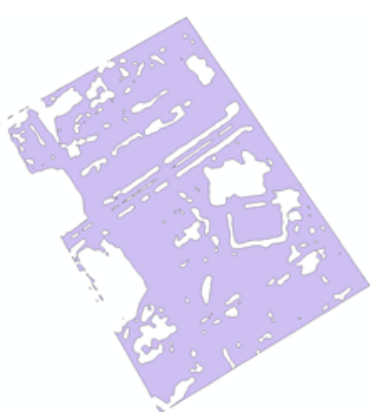

$2019 b$
Figure 5. Extraction area 2 impermeable layer

Figure 1. Selected Area 1 


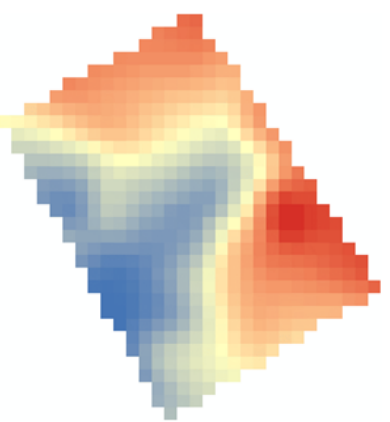

2016b

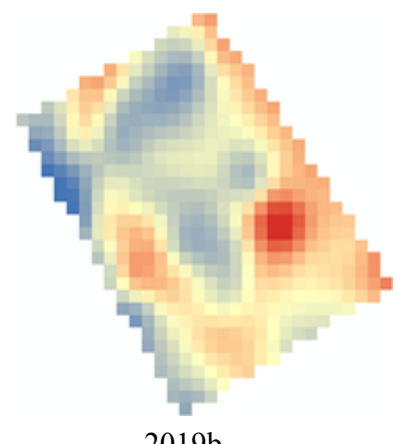

$2019 b$
Figure 6. Inversion Results of Area 2 Surface Temperature

According to the inversion results of surface temperature in area 2 , it is found that the temperature has not changed much after the building area is built, and the temperature increase is not large compared with that before the building area is built. This result is the same as that obtained in Area 1. Compared with the houses and villages built in 19 years, it is found that the temperature of villages is higher than that of houses. This result is due to less vegetation among villages and a lot of greening around the housing area.

\section{Region 3:}

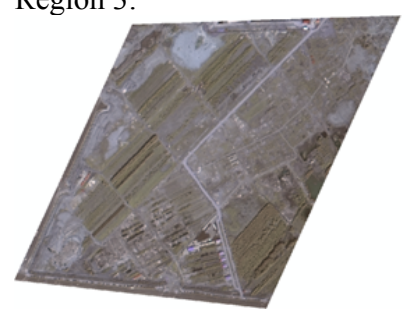

$2016 c$

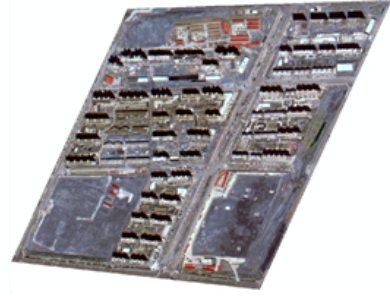

$2019 \mathrm{c}$
Figure 7. Selected Area 3

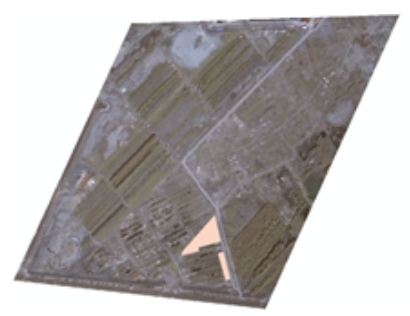

$2016 c$

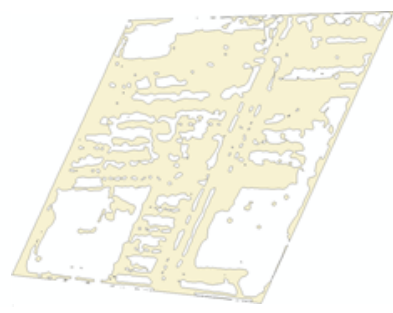

$2019 \mathrm{c}$
Figure 8. Extraction area 2 impermeable layer

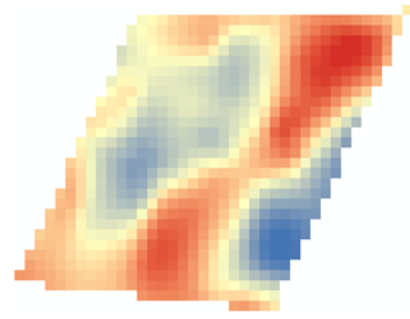

$2016 c$

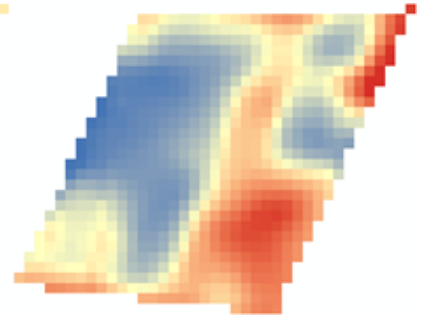

$2019 c$
Figure 9. Inversion Results of Area 2 Surface Temperature

According to the results of Area 1 and Area 2, increasing the greening area around the room area can effectively reduce the amount of heat emitted. The results of area 3 show that if the surrounding of the housing area is afforested reasonably, not only can the heat emitted be controlled, but also the temperature of the housing area can be greatly reduced, providing a suitable living environment for residents.

\subsection{Results Analysis}

There is a significant positive correlation between surface temperature and impervious surface coverage. The higher impervious surface coverage, the higher surface temperature. However, when there is vegetation around the impervious surface and the area of the green space is large, the cooling range and range of the green space are large, while the complex shape of the green space will lead to the shortening of the cooling distance of the green space. The vegetation of the green space grows well and has high vegetation coverage, which can enhance the thermal environment effect of the green space, lengthen the cooling distance of the green space and increase the cooling range.

In cities, the construction of urban greening is one of the important ways to reduce the heat island effect and improve the thermal environment. Understanding the relationship between the spatial pattern of urban greening and the temperature is of positive significance for city managers to design and reasonably plan the city so as to reduce the heat island effect. Based on Landsat 8 TIRS remote sensing images and Gaofen 2 remote sensing images, this study explored the relationship between urban forest spatial pattern and temperature, and clarified the role of urban forest spatial pattern in thermal environment regulation. The relevant conclusions are as follows:

(1) The scale of urban greening is still an important factor to reduce the heat island effect and improve the thermal environment. Increasing urban greening scale (coverage, NDVI) can significantly reduce urban temperature.

(2) In addition to the scale of urban greening, the spatial pattern of urban greening also significantly affects the temperature. Under the given coverage of urban greening, the purpose of increasing or decreasing the city temperature can be achieved by changing the spatial pattern of urban greening. For example, the temperature can decrease with the increase of the maximum plaque index, aggregation degree and connectivity degree. However, it increases with the increase of patch density, landscape shape index and fragmentation.

(3) The relationship between urban greening spatial pattern and temperature changes with the change of research scale. With the increase of research scale, its correlation gradually increases. Therefore, on a larger spatial scale, the spatial pattern of urban greening is more efficient in reducing temperature.

\section{SUGGESTIONS AND COUNTERMEASURES ON GREENING}

According to the results of this study, in order to comprehensively improve the level of urban greening, optimize the layout of green space, enrich the effect of urban landscape, alleviate the negative impact of urban thermal environment effect and even the rapid urbanization in the whole region, and improve the quality of human settlements and ecological environment, the following suggestions and countermeasures are hereby put forward.

\subsection{Establish a Perfect Urban Green Space System}

Greening construction should take park construction as the main body and simultaneously develop roadside greening, residential greening and industrial greening. Although the green space in these areas covers a small area, it can beautify the city, reduce 
pollution and improve the ecological environment of the city, and can be distributed in all parts of the city.

Research shows that, as far as relatively independent green patches are concerned, the level of their ecological benefits will not only vary with the size of green space and the number of vegetation, but also gradually weaken or lose with the increase of spatial distance. Green space composed of a certain number of vegetation has a certain "influence range" in its ecological benefits, which is shown as "locality" corresponding to its scale. This situation is especially prominent under the condition that the urban central area has a strong "offsetting" effect on the ecological benefits of vegetation. Under the condition of the same total area, the ecological effect of scattered greenbelts is greater than that of concentrated greenbelts, especially when large greenbelts are located in one corner of the city.

Therefore, in the ecological planning of green space landscape, how to use the limited green space to realize the relatively uniform distribution of urban garden green space not only plays a significant role in increasing the total amount of garden vegetation in the city, thus expanding its overall ecological benefits, but also has important significance in avoiding or alleviating the deterioration of ecological environment in some areas and maintaining the relative stability of the overal ecological environment quality of the city. Improving the distribution uniformity of urban green space, especially public green space, has become a common understanding of the importance of facilitating urban residents to carry out recreational activities nearby and in preventing and avoiding disasters. Therefore, in principle, public greening and residential greening should be distributed in a balanced way with a suitable area ratio.

Shelter forest belts can be built around residential areas. In order to achieve the best ecological benefits of greening, it is better to plant more trees, select tree species suitable for the site, combine fast-growing and slow-growing tree species, mix deciduous and evergreen tree species, and mix coniferous and broadleaved trees. The beautiful urban green space near the residential area helps to eliminate physical and mental fatigue and mental depression, and meets people's physiological needs. The well-laid green space can also create a relatively private and semi-private space, making people feel comfortable and comfortable, and meeting people's safety needs. On this basis, the urban green space maintains a beautiful, clean and comfortable working and living environment, provides a place for residents to rest and communicate outdoors, and adapts to residents' desire to return to nature and yearn for nature. In the tense and busy city life, the high-grade public green space can relax people's nervous system, make people feel the peace of mind and get the balance of vision and psychology from the endowments of nature. In this way, the green space can create an outdoor living environment with cultural and emotional stimulation, thus creating a unique space situation between human and nature. For example, in Hong Kong parks and highrise buildings, large areas of lush plants are planted to resist the high intensity of buildings with high density of greening, thus forming a strong psychological protection effect on people.

\subsection{Green Corridor Construction}

Two points should be paid attention to in the construction of road corridors: first, the width of the green belt should be widened; second, the diversity of biological species in the green belt should be protected. Specifically, suburban roads are suitable for planting tall street trees to form suburban forest belts, which can not only play a role in greening, but also give visitors entering the city a good first impression. The traffic load of the main roads in the urban area is large and generally relatively broad, and the unity of function and beauty is more important. On both sides of a large river channel, a forest belt with a width of 50-100 meters will be built, some wet tree species will be planted, and some small scenes will be set up on the riverbanks for people's leisure and entertainment. In areas where the water surface in the city is polluted, some pollutionresistant aquatic plants can be planted to cover the water surface, such as water lilies, duckweeds, aquatic flowers and aquatic plants. By constructing the corridor of the river and lake system, the ecological connection between various functional areas and towns can be strengthened, and the sharing of regional ecological support functions can be realized. At the same time, the construction of green corridors in the river and lake systems has also played a role in protecting rivers and conserving water resources.

\section{DEFICIENCIES AND PROSPECTS}

(1) This study did not combine the thermal environment reflected by temperature with the human somatosensory comfort

(2) This study did not carry out the research on the difference characteristics of thermal environmental effects between different urban forest types and different tree species. This is a deficiency of this research, but the next research also points out the direction of improvement.

(3) This study was carried out in Changchun, a typical city in northeast China. Relevant studies show that the characteristics of thermal environmental effects of urban greening may be related to the characteristics of the city. Therefore, whether the conclusion of this study is suitable for other cities needs further study. In addition, this study did not take into account the impact of urban forests on the urban thermal environment, and the impact and mechanism of suburban and suburban urban forests on the urban thermal environment need further in-depth study.

\section{REFERENCES}

[1]Pielke R A. Land use and climate change, Science, 2005, 31 0(5754):1625-1626.

[2]Stone B. Land Use as Climate Change Mitigation. Environm ental Science andTechnology, 2009. 43(24): 9052-9056.

[3] SU Wei-zhong, YANG Ying-bao, YANG Guishan.Distributional characteristics of urban thermal space and relations with land use cover of Nanjing[ J] . Scientia Geographica Sinica, 2005, 25(6): $697 \sim 702$.

[4] ZHOU Hongmei, ZHOU Cheng-hu, GE Wei-qiang,et al. Study of urban heat field distribution rule based on RS and GIS[ J] . Acta Geographica Sinica, 2001, 56( 2): 189 197.

[5] CHANDER G, MARKHAM B. Revised Landsat-5 TM radiometric calibration procedures and post calibration dynamic ranges[J]. IEEE Transactions on Geoscience and Remote Sensing, 2003, 41(11): 2674-2677. 